Revista Brasileira de Cartografia

ISSN 1808-0936 | https://doi.org/10.14393/revbrascartogr

Sociedade Brasileira de Cartografia, Geodésia, Fotogrametria e Sensoriamento Remoto

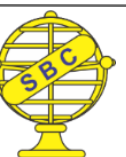

\title{
Posicionamento GNSS em Tempo Real: Evolução, Aplicações Práticas e Perspectivas para o Futuro
}

\author{
Real-time GNSS Positioning: Evolution, Practical Applications and Perspectives for the \\ Future
}

Claudia Pereira Krueger ${ }^{1}$, Paulo Sérgio de Oliveira Junior ${ }^{2}$, Silvio Jacks dos Anjos Garnés ${ }^{3}$, Daniele Barroca Marra Alves ${ }^{4}$ e Jorge Felipe Euriques ${ }^{5}$

1 Universidade Federal do Paraná, Departamento de Geomática, Curitiba, Brasil. cpkrueger64@gmail.com; ckrueger@ufpr.br ORCID: https://orcid.org/0000-0002-4839-1317

2 Universidade Federal do Paraná, Departamento de Geomática, Curitiba, Brasil. paulo.junior@ufpr.br ORCID: https://orcid.org/0000-0001-7000-6924

3 Universidade Federal de Pernambuco, Departamento de Engenharia Cartográfica, Recife, Pernambuco. silvio.jacks@ufpe.br ORCID: https://orcid.org/0000-0002-0098-6645

4 Universidade Estadual Paulista, Departamento de Cartografia, Presidente Prudente, São Paulo, Brasil. daniele.barroca@unesp.br ORCID: https://orcid.org/0000-0002-9033-8499

5 Universidade Federal do Paraná, Departamento de Geomática, Curitiba, Brasil. jorge.euriques@gmail.com ORCID: https://orcid.org/0000-0001-9234-7551

Recebido: 08.2020 | Aceito: 11.2020

Resumo: O posicionamento em tempo real por meio do emprego dos sinais de satélites foi um avanço nas navegações aérea, marítima e terrestre com o surgimento do GPS (Global Positioning System). Contudo as precisões horizontais e verticais de $100 \mathrm{~m}$ e $150 \mathrm{~m}$ (nível de probabilidade de 95\%) alcançadas, estando a SA (Selective Availability) ativada, passaram a não ser satisfatórias para muitas aplicações e os usuários buscaram galgar outros níveis de precisões. Esforços foram investidos no chamado posicionamento diferencial DGPS (Differential GPS), o qual possibilitou obter precisões em torno de dez vezes melhores do que as do posicionamento absoluto. Posteriormente, usando-se a fase da onda portadora, conseguiu-se realizar posicionamento com maior acurácia por meio do método RTK (Real Time Kinematic), atingindo qualidade centimétrica. Na sequência, houve uma evolução para posicionamentos em rede, empregando, por exemplo, o algoritmo de VRS (Virtual Reference Station). Vários erros nas observáveis dos satélites passaram a ser modelados com uma solução de multiestações em tempo real. A partir de 2012, surgiram serviços e produtos que favoreceram o desenvolvimento do RT-PPP (Real-Time Precise Point Positioning) baseado no conceito SSR (State Space Representation). A busca da solução das ambiguidades no RT-PPP deu origem ao PPP-RTK com menor tempo de fixação das ambiguidades e convergência para a solução acurada do posicionamento. Neste artigo apresenta-se como foi a evolução do posicionamento em tempo real, algumas das aplicações no âmbito nacional e as perspectivas desta modalidade de posicionamento para o futuro.

Palavras-chave: DGPS. RTK. PPP-RT. VRS.

Abstract: Real-time positioning using satellite signals was an advance for air, sea and land navigation with the arise of GPS (Global Positioning System). However, the achievable horizontal and vertical accuracy of $100 \mathrm{~m}$ and $150 \mathrm{~m}$ (95\% probability level), when SA (Selective Availability) technique was activated, became unsatisfactory for many applications and users required other accuracy levels. Efforts were dedicated to the so-called differential positioning, DGPS (Differential GPS), which made it possible to achieve precision about ten times better than that usually obtained throughout absolute positioning. Later, using carrier-phase measurements, it was possible to perform positioning with greater accuracy through the RTK (Real Time Kinematic) method, reaching centimeter quality. Subsequently, there was an evolution towards network-based positioning, using, for example, the VRS (Virtual Reference Station) algorithm. Several errors affecting satellite observables started to be modeled in real time with multi-station solutions. As of 2012, services and products were developed in order to accomplish RT-PPP (RealTime Precise Point Positioning), a method based on the SSR (State Space Representation) concept. Further, the ambiguity fixing in RT-PPP became possible, and this approach is usually referred as PPP-RTK, which provides a faster convergence to an accurate positioning solution. This article presents the evolution real time positioning, some applications at the national context, as well as the future perspectives.

Keywords: DGPS. RTK. PPP-RT. VRS. 


\section{INTRODUÇÃO}

A era espacial iniciou-se em 1957, com o lançamento do satélite artificial SPUTNIK-1, pela União Soviética, e com isto surge à concepção da navegação utilizando os sinais de rádio enviados por satélites. A partir de 1960 teve-se o desenvolvimento de sistemas de posicionamento globais por satélites objetivando esta navegação e a determinação de posições sobre a superfície terrestre (SEEBER, 2003; HOFMANNWELLENHOF; LICHTENEGGER ; WASLE, 2008).

Um olhar sobre o passado mostra que quando o Sistema de Posicionamento Global (GPS) se tornou operacional e completo (FOC - Full Operational Capability), em 1995, os usuários foram afetados diretamente pela política de segurança americana (USCG, 1995). Nesta ocasião houve a introdução da Selective Availability (SA) e da Anti-Spoofing (AS), limitando a precisão dos usuários SPS (Standard Positioning Service). A SA consistia na degradação do sinal dos satélites através da manipulação dos dados das efemérides transmitidas e das frequências dos relógios dos satélites (LANGLEY; TEUNISSEN; MONTENBRUCK, 2017). A AS fazia parte da concepção inicial do sistema, a qual não permitia que os usuários civis tivessem acesso ao código $\mathrm{P}$ original, evitando assim qualquer tipo de fraude ao sistema. Nesta época este usuário obtinha para um posicionamento absoluto, instantâneo, ou por ponto, precisões horizontais e verticais de $100 \mathrm{~m}$ e $150 \mathrm{~m}$ (nível de probabilidade de 95\%), respectivamente (SEEBER, 2003; HEGARTY, 2017). Tais precisões eram insuficientes para diversas aplicações que exigiam uma melhor qualidade no posicionamento instantâneo como: a navegação precisa aérea, marítima e terrestre (GREWAL; WEILL; ANDREWS, 2007). Em face desta necessidade surgiu o posicionamento DGPS (Differential GPS), com o qual foi possível eliminar uma grande parcela do efeito SA, proporcionando precisões com valores, pelo menos, dez vezes melhores que os valores citados anteriormente (SEEBER, 2003).

Inicialmente o DGPS era efetuado apenas com a formação de uma linha de base e usando observáveis e correções diferenciais do código e código suavizado pela onda portadora. Posteriormente passou a empregar também as observações e correções da fase da onda portadora com resolução das ambiguidades em tempo real, o método com esta abordagem ficou conhecido por RTK (Real Time Kinematic). Contudo, em face da degradação da acurácia da estação móvel com o aumento do comprimento da linha de base entre estas estações, surgiu outro conceito, o do emprego de rede de estações de referência em tempo real denominada de Network RTK (NRTK) (SEEBER, 2003; ALVES, 2008). Neste caso erros sistemáticos atuantes na região da rede (por exemplo, órbita do satélite, troposfera e ionosfera) passam a ser modelados e incluídos nas informações a serem enviadas às estações móveis localizadas na região de abrangência da rede, melhorando com isto a acurácia do posicionamento e navegação. Se estas redes forem acrescidas de satélites geoestacionários para o envio das informações, tem-se então, os sistemas aumentados por satélites (SBAS - Satellite Based Augmentation System), por exemplo, WAAS - Wide Area Augmentation System e EGNOS - European Geostationary Navigation Overlay System (GREWAL; WEILL; ANDREWS, 2007; LANGLEY; TEUNISSEN; MONTENBRUCK, 2017).

Nas últimas décadas surgiu o PPP (Precise Point Positioning) e sua variante em tempo real, PPP-RT (PPP Real Time), os quais continuam sendo aprimorados (GRINTER; ROBERTS, 2011). No PPP a estação móvel é posicionada por meio de seus dados acrescidos de correções precisas para as órbitas e relógios dos satélites rastreados. Um avanço está ocorrendo no que concerne à determinação das ambiguidades inteiras, em poucos minutos, possibilitando ao usuário alcançar precisões centimétricas em tempo real. O PPP-RT com solução das ambiguidades tem recebido a nomenclatura de PPP-RTK (WÜBBENA et al., 2005; TEUNISSEN; KHODABANDEH, 2015). Dessa forma, o PPP-RTK tem se mostrado bastante promissor, uma vez que seus resultados na literatura indicam que o método pode ser utilizado com redes de referência mais esparsas que o tradicional NRTK. Entretanto, para usuários que necessitam de resultados comparáveis ao RTK (i.e soluções instantâneas com $1 \sim 2 \mathrm{~cm}$ de erro), o método PPP-RTK tem sido considerado uma solução complementar de menor custo para atender regiões onde não se tem disponível cobertura NRTK (ROVIRA-GARCIA; JUAN; GONZALES-CASADO, 2015; OLIVEIRA JR, 2017).

Ao longo deste artigo apresenta-se a evolução dos posicionamentos em tempo real, com as suas 
devidas peculiaridades, bem como, os serviços disponíveis no Brasil. Posteriormente descrevem-se algumas aplicações práticas com os resultados alcançados ao longo dos últimos anos. Por fim, são apresentadas as perspectivas destes métodos de posicionamento para os próximos anos.

\section{EVOLUÇÃO DO POSICIONAMENTO EM TEMPO REAL}

Conforme exposto anteriormente o posicionamento por satélites teve uma evolução ao longo das últimas décadas, associada a diversos fatores, dentre eles citam-se: a observável, o sistema de comunicação e o formato para transmissão das correções diferenciais. Estes fatores serão abordados na sequência.

\subsection{Tipos de posicionamento em tempo real}

\subsubsection{POSICIONAMENTO ABSOLUTO}

Dentre as possibilidades de obtenção de coordenadas geodésicas instantâneas tem-se o posicionamento absoluto. Ele fornece ao usuário as coordenadas do ponto ocupado pelo equipamento (receptor/antena) em relação ao geocentro de um sistema geodésico de referência, por exemplo, WGS-84 (GPS) e PZ-90 (GLONASS) (MONICO, 2008). Estas coordenadas são calculadas instantaneamente com as informações das efemérides dos satélites e as pseudodistâncias medidas pelo receptor de uma das observáveis como L1, L2, L5 ou combinação linear dessas. Esse tipo de posicionamento fornecia precisões horizontais e verticais melhores que $13 \mathrm{~m}$ e $25 \mathrm{~m}$ (nível de probabilidade de 95\%), respectivamente, com a constelação básica GPS (DIVIS, 2000; SEEBER, 2003). Atualmente em face das constelações existentes e do número de satélites observados, são esperadas melhores precisões para o posicionamento absoluto, conforme estudos efetuados, por exemplo, por Euriques, Krueger e Silva (2018). Dentre as constelações do GNSS (Global Navigation Satellite Systems) tem-se: GPS (31 satélites); GLONASS (29 satélites), BeiDou (27 satélites); GALILEO (não declarado operacional - atualmente 22 satélites em funcionamento). Segundo Gao e Enge (2012), até o ano de 2030 estes sistemas deverão proporcionar 120 satélites em órbita aos usuários do GNSS. No entanto, em face da realidade atual, esse número de satélites deverá ser alcançado antes dessa data.

\subsubsection{POSICIONAMENTO DIFERENCIAL}

O posicionamento diferencial (Figura 1) consiste no posicionamento de uma estação móvel através das correções diferenciais geradas em uma estação de referência enviadas em tempo real por meio de um sistema de comunicação (rádio de transmissão, linha telefônica ou satélites de comunicação). Estas correções devem estar em um formato apropriado, definido pela Radio Technical Committee for Maritime Service (RTCM) (SEEBER, 1993; KRUEGER, 1996). As estações devem observar simultaneamente pelo menos 4 satélites, e as coordenadas acuradas da estação de referência devem ser conhecidas a priori. Este tipo de posicionamento possibilita a minimização dos erros dos relógios, das órbitas dos satélites, e da propagação do sinal na atmosfera para linhas de base curtas.

O posicionamento diferencial em tempo real recebe diferentes nomenclaturas na literatura, por exemplo: quanto ao número de estações de referência envolvidas (uma estação ou rede dessas estações); quanto ao tipo de observável (código, código suavizado pela onda portadora ou onda portadora); quanto às correções (escalares ou vetoriais) empregadas no cálculo da coordenada da estação móvel; e quanto à precisão a ser obtida. Focando-se na observável empregada, têm-se três diferentes grupos:

a) DGNSS aplicando correções diferenciais das pseudodistâncias por meio do código, que pode fornecer precisões no posicionamento da estação móvel entre 1 a 3 m, dependendo do comprimento da linha de base formada entre as estações empregadas;

b) DGNSS aplicando correções diferenciais das pseudodistâncias por meio do código 
suavizado pela onda portadora (exemplo, filtro de Lachapelle), possibilitando precisões melhores que 0,5 m na estação móvel;

c) DGNSS aplicando correções diferenciais da fase da onda portadora ou da própria observável da fase da portadora, denominado de diferencial preciso ou RTK, que permite precisões na ordem do centímetro (WILLIGALIS et al., 2002).

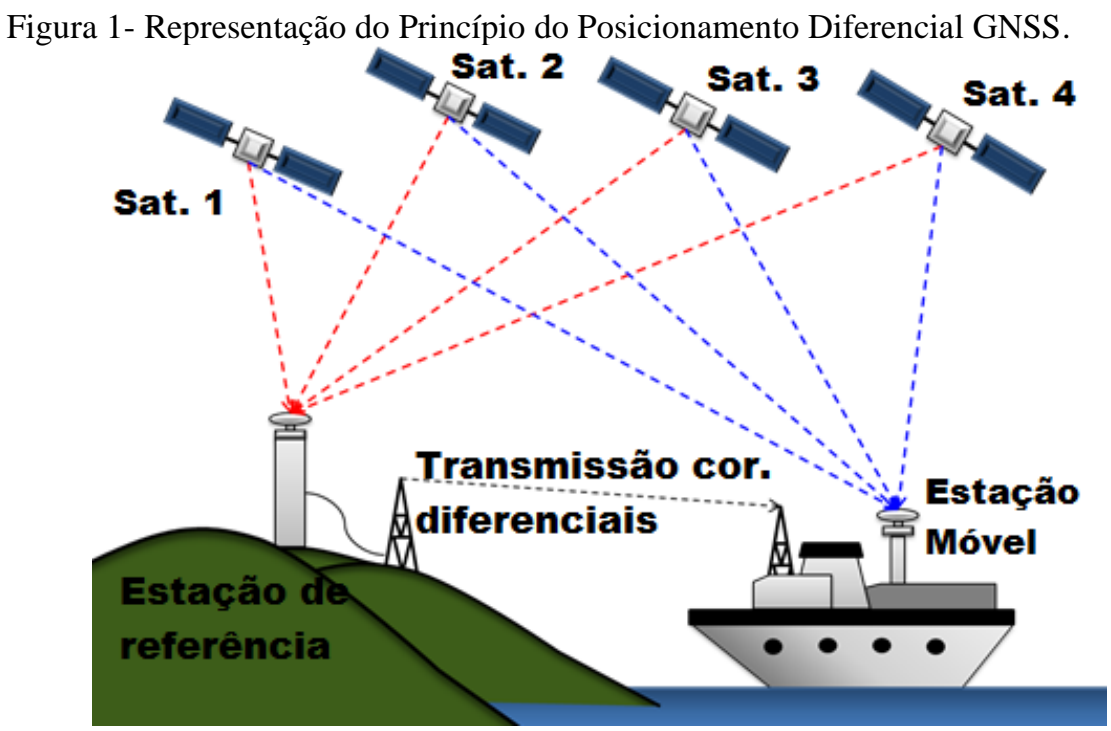

Fonte: Adaptado de KRUEGER (1996).

No que tange as correções diferenciais empregadas pela estação móvel, tem-se:

a) no domínio das posições;

b) no domínio das pseudodistâncias; e

c) no domínio do espaço.

No item a, conhecidas as coordenadas acuradas da estação de referência, são calculadas as diferenças entre elas e as coordenadas obtidas instantaneamente. Estas diferenças são enviadas à estação móvel de forma a corrigir a sua posição instantânea em tempo real. É um processo simples, contudo, é eficiente apenas para linhas de base curtas onde ambas as estações recebem sinais dos mesmos satélites simultaneamente.

No caso b, das correções serem consideradas no domínio das pseudodistâncias, tem-se que elas são provenientes da diferença entre as pseudodistâncias verdadeiras e as pseudodistâncias calculadas para cada um dos satélites observados na estação de referência. Esta forma é mais flexível, havendo apenas a necessidade da constelação de satélites da estação móvel ser uma subconstelação de satélites observados na estação de referência. Desta forma, pode-se operar com linhas de base de vários quilômetros, sabendo-se que a precisão da estação móvel diminui cerca de $1 \mathrm{~m}$ a cada $100 \mathrm{~km}$ (SEEBER, 2003) devido à redução da similaridade entre os erros de órbita do satélite e da atmosfera (troposfera e ionosfera) com o aumento da linha de base formada.

O caso c, das correções no domínio do espaço, é aplicado em redes de estações de referência, possibilitando o posicionamento em maiores distâncias e a modelagem de erros sistemáticos. Este processo se baseia na correção de vetores e não em correções escalares, como acontece no segundo processo, com isso, o posicionamento da estação móvel será mais preciso na área de abrangência das estações de referência empregadas.

Para contornar a degradação da acurácia do posicionamento da estação móvel frente ao aumento do comprimento da linha de base, surgiu o posicionamento diferencial em rede. Esse posicionamento consiste em empregar simultaneamente diversas estações de referência, podendo ter alcance de um país ou até um continente. Desta forma, os erros são modelados e estimados na região. Correções são geradas e 
posteriormente enviadas às estações móveis, possibilitando maior acurácia no seu posicionamento (FOTOPOULOS; CANNON, 2001), (LACHAPELLE; ALVES, 2002), (SEEBER, 2003), (BROWN et. al., 2005). Outro benefício consiste no aumento de confiabilidade e disponibilidade do serviço. De acordo com Fotopoulos e Cannon (2001), contribuições de estações de referência que apresentem falhas podem ser eliminadas e a solução é gerada somente pelas demais estações ativas.

A literatura indica que pelo menos três conceitos podem ser aplicados no que se refere ao cálculo das correções e a forma de envio ao usuário no caso de rede de estações de referência: Parâmetros de Correção de Área (FKP - Flächenkorrekturparameter ou ACP - Area Correction Parameter), Estações de Referência Virtuais (VRS - Virtual Reference Stations) e Master - Auxiliary Concept - MAC.

No conceito FKP para cada satélite são calculados coeficientes que representam os efeitos de ionosfera, órbita e troposfera para uma área limitada pela rede formada e para um determinado intervalo de tempo (WÜBBENA et al., 1996). Este cálculo é realizado por uma estação principal. As correções e os coeficientes são enviados ao usuário, no formato RTCM, de forma que ele possa efetuar a interpolação dos erros e determinar a sua posição (SEJAS et al., 2002).

Segundo Alves (2008), no conceito de estação virtual, as correções da rede são utilizadas para gerar dados de fase e pseudodistância de uma estação que não existe fisicamente, mas que simule uma estação de referência nas proximidades do usuário. Com os dados dessa estação VRS, situada a poucos metros do usuário, é possível realizar o posicionamento relativo e determinar a sua posição.

No terceiro conceito (MAC) todos os dados relevantes referentes às correções da rede devem ser transmitidos para o usuário (BROWN et al., 2005). É empregado o formato RTCM 3.0 utilizando correções da estação principal (master) e diferenças de correções para as estações auxiliares. A posição precisa do usuário será determinada utilizando as informações transmitidas pela rede (SEJAS; KRUEGER, 2007).

As redes utilizadas para posicionamento em tempo real de acordo com a sua abrangência e observáveis empregadas podem receber diferentes denominações, como: Local Area (LADGNSS); Wide Area (WADGNSS); NRTK (SEEBER, 2003). Na LADGNSS correções diferenciais escalares são aplicadas em áreas com raio de até $1000 \mathrm{~km}$, a cada um dos satélites observados. Neste caso, apenas um valor representa todas às influências dos erros atuantes na estação de referência, ou no caso de mais estações, ocorre uma ponderação obtendo-se um valor médio. A WADGNSS emprega um vetor de correções para cada satélite, derivadas de observações efetuadas por diversas estações de referência que compõem a rede continental ou global. Este vetor é composto de correções individuais para cada relógio do satélite, posição do satélite e modelo de atraso ionosférico. Este vetor de correções é válido para grandes áreas de abrangência. A WADGPS foi a primeira a ser desenvolvida, ela empregava as medidas das pseudodistâncias com os códigos em uma rede continental (KEE et al., 1991) e proporcionava correções diferenciais para a navegação marítima, aérea e terrestre possibilitando que a estação móvel tivesse melhores precisões. Segundo Grewal, Weill e Andrews (2007), as correções são enviadas em tempo real por um satélite de comunicação geoestacionário ou através de uma rede de transmissores terrestres. Na Figura 2 percebe-se que nos casos em que as ambiguidades permanecem flutuantes, ou seja, com suas soluções reais, as precisões obtidas são do decímetro e do metro, operando com linhas de base de até $1000 \mathrm{~km}$ (WILLIGALIS et.al., 2002).

Na NRTK são empregadas às observações da fase da onda portadora podendo ser aplicado os conceitos FKP, VRS ou MAC. Alves (2008) destaca que independentemente do método usado, algumas etapas devem ser observadas: realizar a solução das ambiguidades entre as estações de referência, calcular as correções da rede, e transmitir os dados ou as correções geradas para o usuário.

Na Figura 2 observa-se que em NRTK com linhas de base inferiores a $100 \mathrm{~km}$ e solução das ambiguidades no conjunto dos inteiros, a precisão alcançada pelo usuário pode ser de poucos centímetros.

Na Figura 3 visualizam-se duas redes de referência RTK locais que foram implantadas no Brasil, por 15 dias, dentro de um projeto de cooperação internacional entre o Brasil (UFPR e UFPE) e a Alemanha (IfE/UH) de 1998 a 2001. A estação principal recebia as correções geradas pelas demais estações de referência e calculava parâmetros de correção de superfície (FKP) para a área, buscava resolver as 
ambiguidades inteiras (GNRT/GNNET) e gerava novas correções diferenciais a serem enviadas para a estação móvel, através de rádios UHF (Ultra High Frequency). Atualmente, no Brasil, existem estudos científicos relativos ao NRTK em continuidade ao sistema desenvolvido por Alves (2008). Mas, em termos de serviços operacionais, apenas sistemas comerciais estão disponíveis.

Figura 2 - Precisão dependente da linha de base para os diferentes métodos de posicionamento no pós-processamento e em tempo real, levando-se em conta a determinação do número inteiro de ciclos das ambiguidades ( $a m b$ fixed) e com a determinação das ambiguidades no conjunto dos reais (amb float).

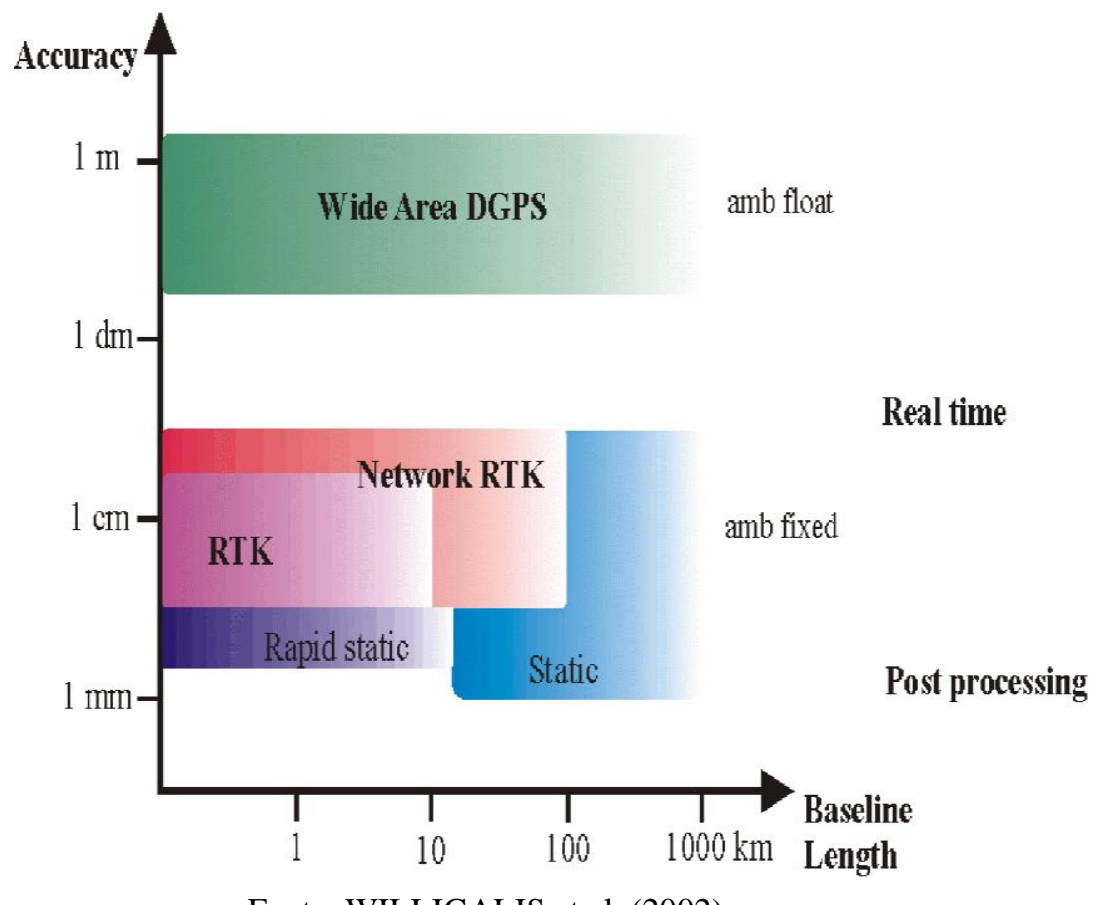

Fonte: WILLIGALIS et al. (2002).

Figura 3 - Exemplos de Redes Locais RTK no Brasil: a) Rede RTK no litoral paranaense (1999) formada por 4 estações de referência sendo CEM2 (estação principal); PARG; GUAR e ANTO. A distância entre a estação principal e as estações de referência foi inferior a 27 km; b) Rede RTK em Pernambuco (2000) formada por 4 estações de referência sendo RECF (estação principal); 3aDL; SOLA e TELE. A distância entre a estação principal e as estações de referência foi inferior a $20 \mathrm{~km}$.

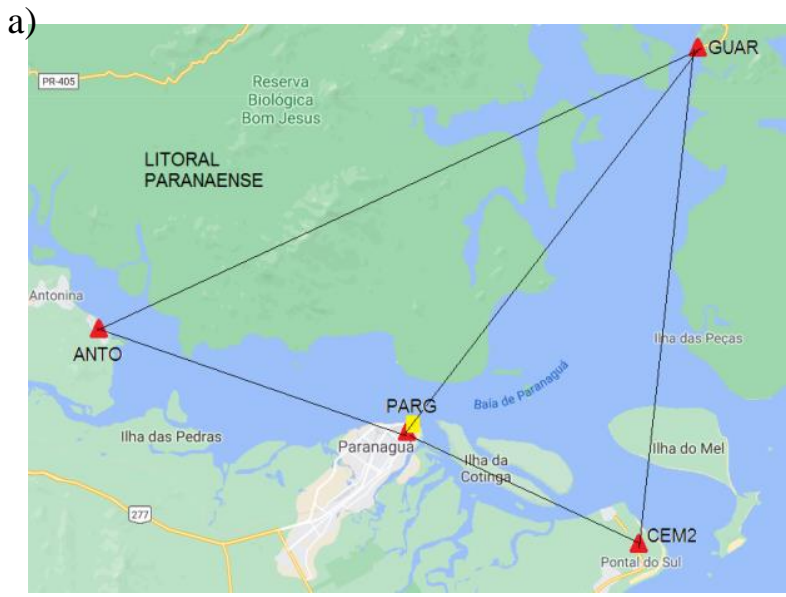

Fonte: KRUEGER et al. (2001).

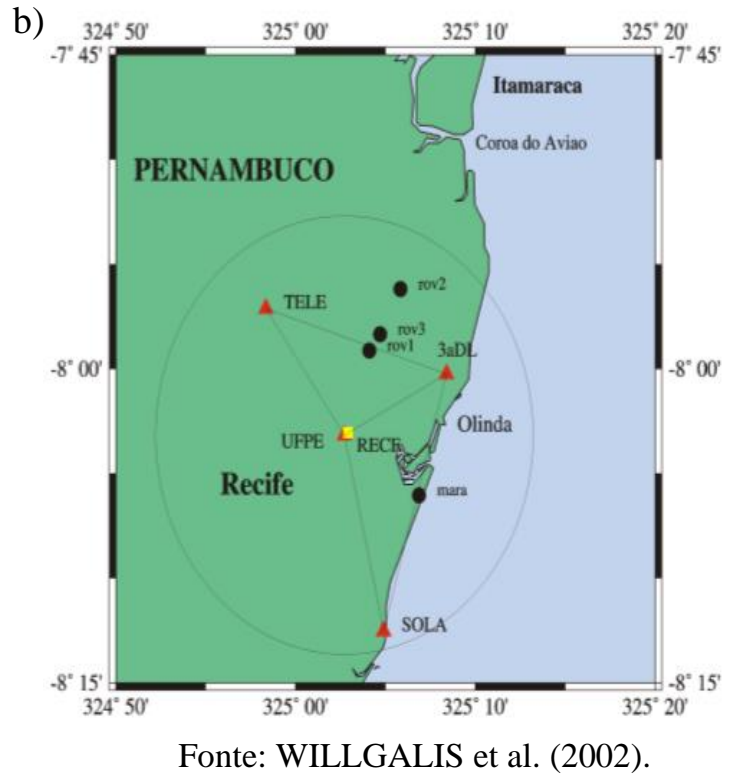

No contexto dos posicionamentos em tempo real destacam-se ainda os serviços SBAS (Satellite Based Augmentation System). Eles são compostos de estações de referência e estações principais, bem como, 
antenas de transmissão terrestres que enviam as correções diferenciais para satélites geoestacionários, retransmitindo para os usuários (Figura 4). Os SBAS foram projetados para melhorar a qualidade de um sistema GNSS, como por exemplo: precisão, robustez e disponibilidade de sinal. Dentre as principais características dos SBAS cita-se: a integridade, a disponibilidade e o fornecimento de serviço contínuo aos usuários.

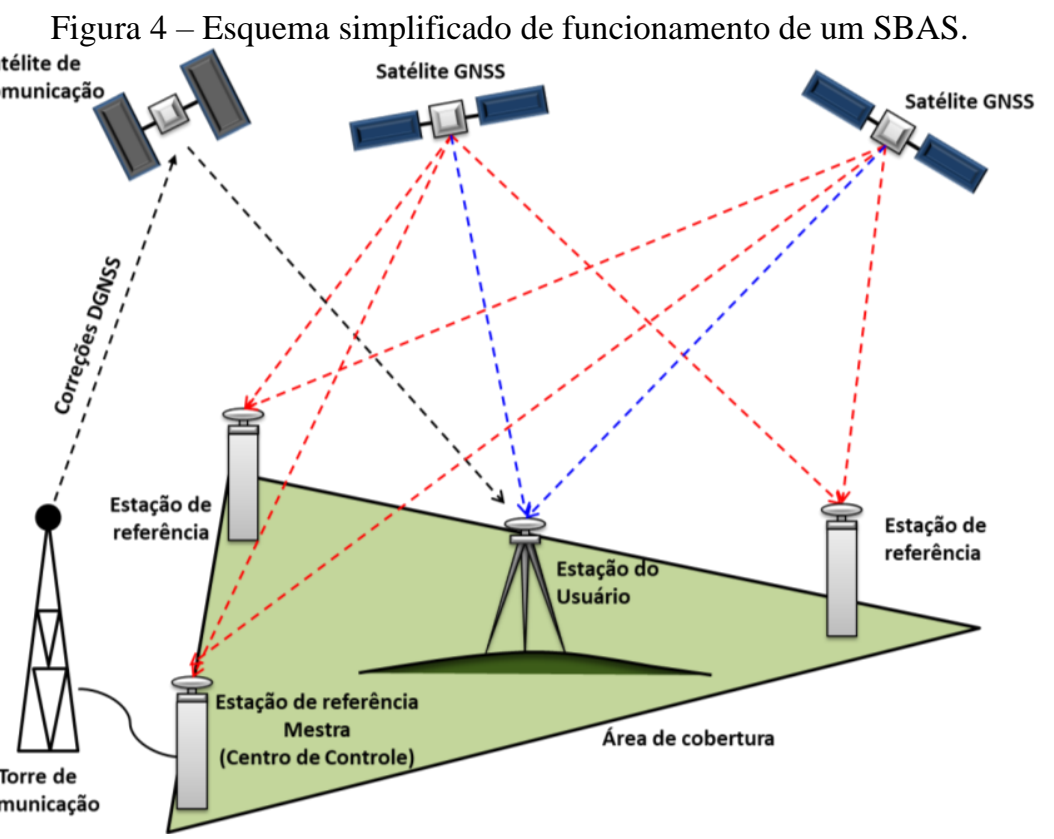

Fonte: Adaptado de TEUNISSEN e MONTEBRUCK (2017).

O WAAS - Wide Area Augmentation System (USA), o EGNOS - European Geostationary Navigation Overlay System (Europa) e o MSAS - Satellite Based Augmentation System (Japão) são exemplos de SBAS. Segundo Flament, Thompson e Ahmad (2020), o grupo de trabalho do SBAS (SBAS IWG) iniciou em 1997 com 4 membros e agora conta com mais de 10 membros. Na Figura 5 visualizam-se os SBAS em operação e aqueles que estão em definição ou desenvolvimento. O Brasil não possui um serviço SBAS e, apesar de poder receber correções diferenciais dos satélites geoestacionários dos SBAS em operação, elas não são satisfatórias, visto que, o Brasil não se encontra dentro de nenhuma das áreas de definição dos serviços existentes.

Figura 5 - Sistemas SBAS. Os sistemas em operação estão indicados pelos retângulos em azul, contendo o ano de funcionamento, sendo: CWAAS do Canadá, WAAS dos Estados Unidos, EGNOS da Europa, GAGAN da Índia e MSAS do Japão. Nos retângulos amarelos visualizam-se os sistemas que se encontram em definição ou desenvolvimento, sendo indicado o ano previsto do funcionamento: BDSBAS da China, KASS da Coreia do Sul, ASECNA da África Oriental e Oceano Índico, SDCM da Rússia, SPAN da Austrália e Nova Zelândia.

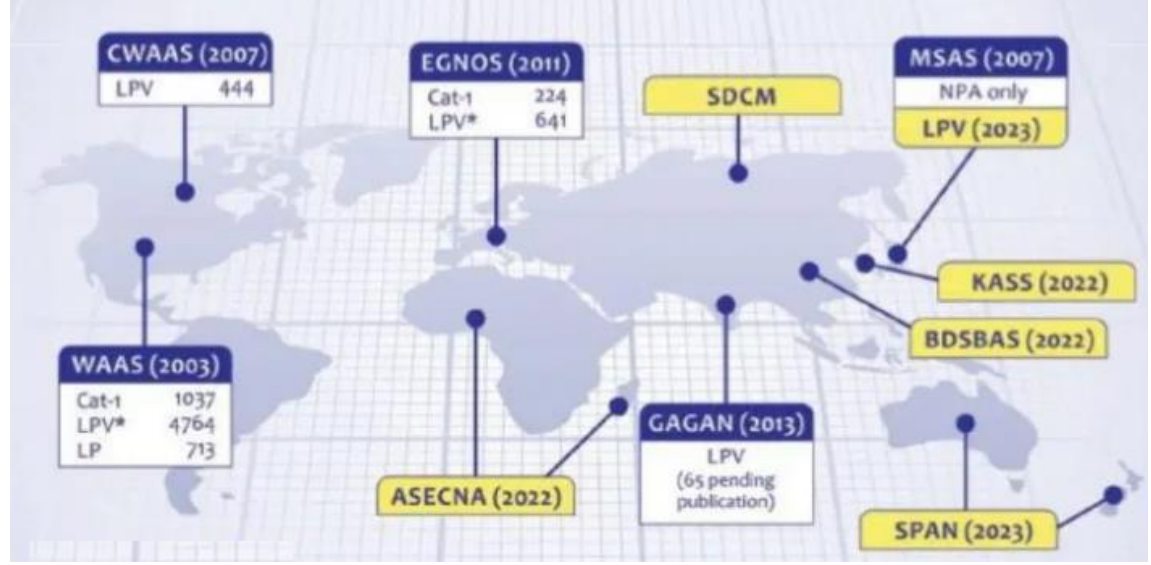

Fonte: FLAMENT, THOMPSON e AHMAD (2020). 


\subsubsection{PPP EM TEMPO REAL}

O PPP-RT consiste no posicionamento a partir de apenas uma estação, a qual necessita receber correções de órbitas e relógios dos satélites em tempo real. Neste âmbito, em 2007 o IGS iniciou um projeto piloto utilizando observações GNSS em tempo real obtidas de uma rede global. Em 2010 esta instituição criou o grupo de trabalho RTWG (Real Time Working Group), e em abril de 2013, lançou oficialmente o serviço RTS (Real Time Service) cujos produtos oficiais incluem as correções. Com o emprego dos produtos obtidos com redes GNSS globais, a acurácia centimétrica tornou-se factível no PPP-RT (GRINTER; ROBERTS, 2011; RIZOS et al., 2012). Neste método o tempo necessário para a coleta de dados de observação e transformação de coordenadas para o sistema de referência almejado ainda são fatores limitantes. No Brasil, destaca-se o trabalho de Marques (2012), com implementação da estimativa e aplicação das correções dos relógios dos satélites no PPP-RT. Nesse estudo, foram realizados diversos experimentos com resultados de qualidade centimétrica e decimétrica, para PPP-RT estático e cinemático, respectivamente.

A estratégia de PPP-RT padrão requer a estimativa de parâmetros de estado (por exemplo, atrasos troposféricos) conjuntamente com as ambiguidades float, o que exige um tempo de inicialização considerável (no mínimo $30 \mathrm{~min}$ ) para alcançar convergência apropriada ao ajustamento sequencial dos valores reais das ambiguidades, ainda que sob-boas condições de geometria dos satélites (ROVIRA-GARCIA; JUAN; GONZALES-CASADO, 2015). Contudo, a possibilidade de acelerar a convergência da solução no PPP-RT utilizando-se correções SSR (State Space Representation) de estações de referência tem sido bastante explorada, nesse caso, a vantagem em relação ao NRTK consiste no uso de comunicação mono-direcional com os usuários e a possibilidade de adoção de uma rede de estações de referência mais esparsa (OLIVEIRA JR et al., 2017).

Segundo Teunissen e Khodabandeh (2015), a possibilidade de fixar as ambiguidades para valores inteiros no PPP-RT tem sido explorada, sendo denominado PPP-RTK. Os produtos da rede de estações de referência para o PPP-RTK podem incluir correções de tendência instrumental dos satélites nas medidas de fase (Figura 6) que facilitam a solução das ambiguidades (N) (LAURICHESSE; PRIVAT, 2015; OLIVEIRA JR et al., 2020). Na ausência de anomalias ionosféricas e de multicaminho o tempo de convergência padrão do PPP-RTK é de alguns minutos (2 10 min) dependendo de vários fatores, i.e. implementação, correções aplicadas, topologia da rede, entre outros. Nesse sentido, em nível nacional, destaca-se a pesquisa de Lima (2015).

Figura 6 - Interpretação geométrica das ambiguidades e da tendência instrumental nas medidas de fase durante a passagem de um satélite.

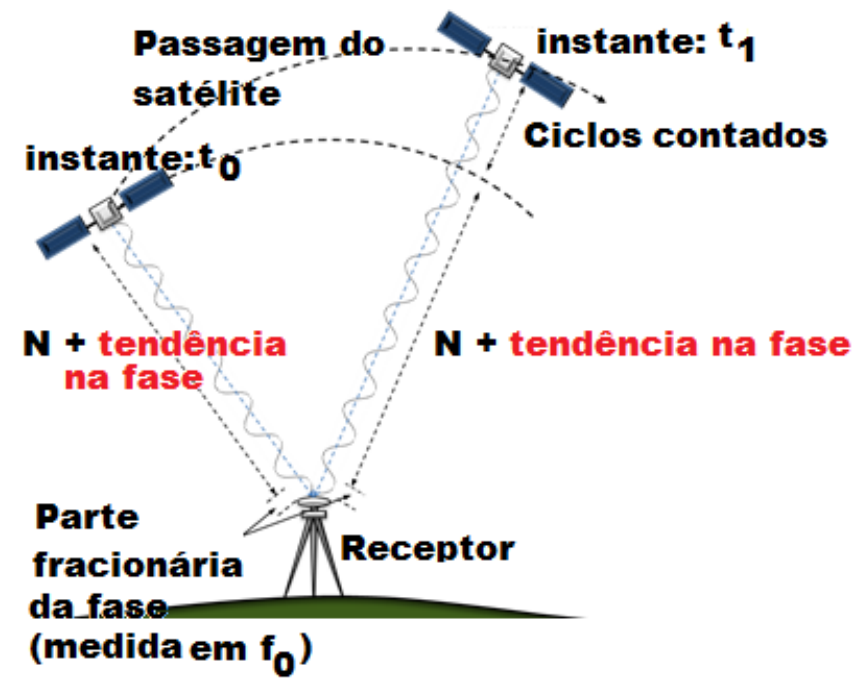

Fonte: Adaptado de LIMA (2015). 
Resultados de PPP-RTK incluindo também a aplicação de correções SSR para parâmetros atmosféricos, tais como os atrasos ionosférico e troposférico, têm demonstrado melhorias com convergência ao nível do centímetro nos primeiros minutos ou mesmo segundos (LI et al., 2014; ROVIRA-GARCIA; JUAN; GONZALES-CASADO, 2015). Esses estudos mostram o posicionamento baseado em correções SSR como uma solução independente ou complementar aos métodos de RTK ou NRTK. É válido frisar que para as aplicações em que exigem convergência instantânea com acurácia centimétrica, o NRTK ainda se impõe como alternativa para serviços de rede. O PPP-RTK tem se apresentado como uma solução menos onerosa, capaz de atender usuários que necessitam de acurácia melhor que $10 \mathrm{~cm}$ e com tempo de convergência de alguns minutos. No entanto, as performances da modelagem atmosférica para geração de correções SSR dependem da topologia da rede e das condições atmosféricas. No caso do Brasil a modelagem da ionosfera é um desafio à parte, haja vista a anomalia equatorial e a ocorrência de irregularidades devido à cintilação ionosférica. A Figura 7 ilustra um exemplo de fluxo de dados e etapas para a realização de PPP-RTK com correções atmosféricas (OLIVEIRA JR, 2017).

Figura 7 - Esquema para realização do PPP-RTK, com geração de correções atmosféricas SSR e aplicação das mesmas no posicionamento do usuário.

Rede de referência

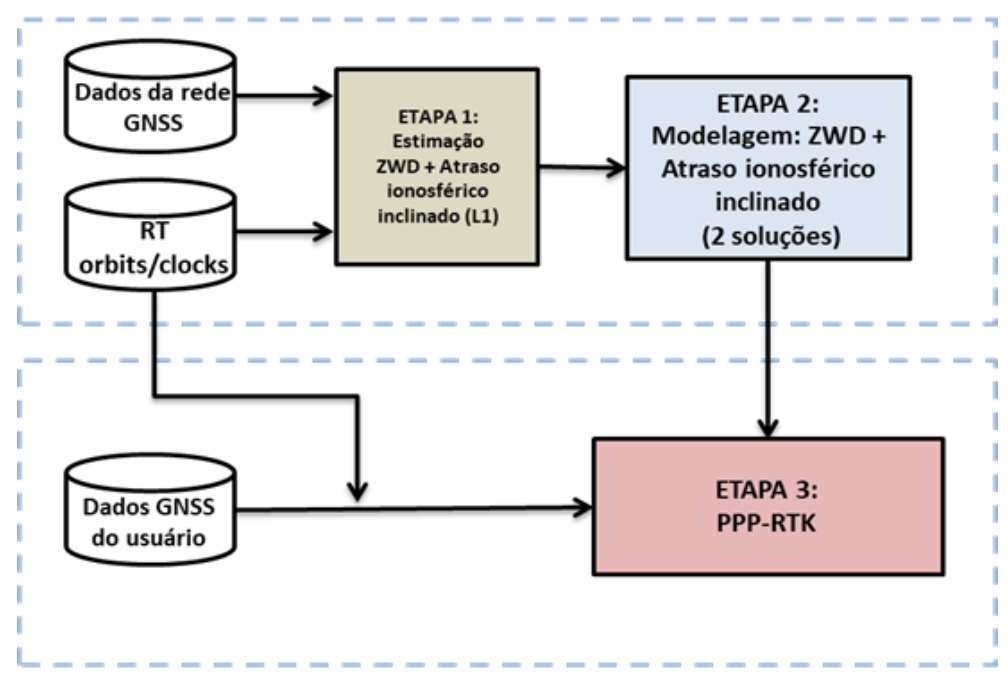

Usuário

Fonte: OLIVEIRA JR. (2017).

\subsection{Formato para Transferência dos Dados e Correções Diferenciais}

Conforme exposto anteriormente, as correções diferenciais e dados são enviados em tempo real por meio de um sistema de comunicação e dentro de um formato apropriado. Com o desenvolvimento do DGPS, o U.S. Institute of Navigation (ION), em 1983, solicitou à RTCM o desenvolvimento de recomendações para a transmissão das correções diferenciais para os usuários do sistema (KRUEGER, 1996). Este serviço fundou o Comitê Especial 104 (SC - 104) que é responsável pela disseminação e definição dos padrões para os sistemas diferenciais GNSS, que são utilizados mundialmente para navegação por satélite (marítima ou terrestre). Em 1985 foi publicada a primeira versão, a qual vem sendo aprimorada continuamente. Um panorama desta evolução é indicado no Quadro 1, destacando-se a versão, o ano de publicação, as principais mensagens e demais especificidades (RTCM, 2006). 
Quadro 1 - Versões e revisões do RTCM-SC104.

\begin{tabular}{|c|c|c|c|}
\hline Versão & Ano & Mensagens principais & $\begin{array}{c}\text { Usuários do posicionamento } \\
\text { diferencial/sistema }\end{array}$ \\
\hline 1.0 & 1985 & Implementação. Houve problemas operacionais. & DGPS (código) / GPS. \\
\hline 2.0 & 1990 & $\begin{array}{l}\text { 1 - Correções diferenciais GPS. } \\
21 \text { - Variação das correções diferenciais. } \\
3 \text { - Parâmetros da estação de referência. }\end{array}$ & $\begin{array}{l}\text { DGPS (código e código suavizado) } \\
\text { / GPS. }\end{array}$ \\
\hline 2.1 & 1994 & $\begin{array}{l}\text { Versão } 2.0 \text { + Mensagens } 18 \text { a } 21 . \\
18 \text { - Fase da onda portadora não corrigida. } \\
19 \text { - Pseudodistâncias não corrigidas. } \\
20 \text { - Correções diferenciais RTK da fase da onda } \\
\text { portadora. } \\
21 \text { - Correções diferenciais RTK da } \\
\text { pseudodistâncias. }\end{array}$ & $\begin{array}{l}\text { DGPS e RTK (código, código } \\
\text { suavizado e fase da onda } \\
\text { portadora) / GPS. }\end{array}$ \\
\hline 2.2 & 1998 & $\begin{array}{l}\text { Versão } 2.1 \text { + Mensagens } 31 \text { a } 36 \text { (para GLONASS) } \\
+37 . \\
31 \text { - Correções diferenciais. } \\
32 \text { - Parâmetros da estação de referência. } \\
33 \text { - Saúde da constelação. } \\
34 \text { - Correções diferenciais de uma parcela dos } \\
\text { satélites. } \\
37 \text { - Diferença de tempo do sistema GNSS. }\end{array}$ & $\begin{array}{l}\text { DGPS e RTK (código, código } \\
\text { suavizado e fase da onda } \\
\text { portadora) / GPS e GLONASS. }\end{array}$ \\
\hline 2.3 & 2001 & $\begin{array}{l}\text { Versão } 2.2 \text { + Mensagens } 23 \text { e } 24 . \\
23 \text { - Tipo de antena. } \\
24 \text { - Variações do Centro de Fase da Antena (PCV). }\end{array}$ & $\begin{array}{l}\text { DGPS e RTK (código, código } \\
\text { suavizado e fase da onda portadora } \\
\text { / GPS e GLONASS. }\end{array}$ \\
\hline $\begin{array}{l}3.0 \\
\text { (RTCM Paper 30- } \\
2004 \text { / SC104-STD) }\end{array}$ & 2004 & $\begin{array}{l}\text { Versão } 2.3+\text { Mensagens reformuladas. } \\
13 \text { tipos de mensagens reformuladas }(1001,1002 \ldots \\
1013) \text {. } \\
\text { Mensagens para suportar operações em tempo real } \\
\text { incluindo código observável e fase de portadora, } \\
\text { parâmetros de antena e parâmetros auxiliares do } \\
\text { sistema. }\end{array}$ & $\begin{array}{l}\text { RTK (fase da onda portadora) / } \\
\text { GPS e GLONASS. }\end{array}$ \\
\hline $\begin{array}{l}\text { 3.1 ou RTCM } \\
\text { Standard } 10403.1\end{array}$ & 2006 & $\begin{array}{l}\text { Versão } 3.0+\text { correções RTK em rede (conceito } \\
\text { Master-Auxiliary) + Parâmetros de órbita para } \\
\text { auxiliar na aquisição rápida. } \\
\text { Uma mensagem de texto é fornecida para a } \\
\text { transmissão de dados textuais. } \\
\text { Um conjunto de mensagens é reservado para } \\
\text { fornecedores que desejam encapsular dados } \\
\text { proprietários em suas transmissões. }\end{array}$ & $\begin{array}{l}\text { RTK (fase da onda portadora) em } \\
\text { Rede / GPS e GLONASS. }\end{array}$ \\
\hline $\begin{array}{l}3.2 \text { ou RTCM } \\
10403.2\end{array}$ & 2013 & $\begin{array}{l}\text { Versão } 3.1+5 \text { emendas } 3.0 \text { + Mensagens de Sinal } \\
\text { Múltiplo (MSM) + Integração com outras } \\
\text { constelações + Efemérides do GLONASS e QZSS. }\end{array}$ & $\begin{array}{l}\text { Network RTK (fase da onda } \\
\text { portadora) / GPS, GLONASS } \\
\text { (GNSS) além da integração como } \\
\text { Galileo, BeiDou, QZSS. }\end{array}$ \\
\hline 3.3 & 2016 & $\begin{array}{l}\text { Suporte aos sistemas aumentados por satélites } \\
\text { (SBAS). } \\
\text { Adiciona efemérides do BeiDou. }\end{array}$ & \\
\hline $\begin{array}{l}\text { 10.1 ou RTCM } \\
10410.1\end{array}$ & 2004 & $\begin{array}{l}\text { Padroniza o protocolo utilizado para a realização de } \\
\text { transmissões de mensagens GNSS através da } \\
\text { Internet, chamado NTRIP, que pode ser acessado } \\
\text { através de serviços móveis de transmissão do } \\
\text { protocolo IP. }\end{array}$ & $\begin{array}{l}\text { Fase da Onda Portadora/ NTRIP/ } \\
\text { GNSS. }\end{array}$ \\
\hline
\end{tabular}

Fonte: Adaptado de RTCM (2006) e SEEBER (2003).

\subsection{Sistemas de Comunicação}

O sistema de comunicação influencia diretamente na qualidade do posicionamento diferencial em tempo real. A transmissão das correções ou dados da estação de referência para a móvel deve ser feita de forma a garantir a integridade destas informações e seguir as normas estabelecidas pelo Comitê Especial SC 
104. Segundo Heimberg (1994), as altas frequências possibilitam uma melhor solução, conduzindo, dessa forma, a uma alta precisão. Quanto mais curto for o comprimento de onda, mais elevada é a taxa de transmissão de dados, porém menor é o alcance. No Quadro 2 são indicados alguns sistemas de comunicação com algumas características para diferentes tipos de posicionamento em tempo real. Neste quadro pode-se verificar, por exemplo, que para NRTK os meios de transmissão Radio $70 \mathrm{~cm}$, Telefonia Celular e Internet são recomendados possibilitando a transmissão dos dados com a taxa de $9600 \mathrm{bit} / \mathrm{s}$.

Dentre estes meios de comunicação pode-se destacar que as transmissões VHF e UHF apresentam instalações simples e de menor custo, contudo a confiabilidade do sistema pode ser afetada pelo efeito de multicaminho. Diversas empresas oferecem, atualmente, rádios com múltiplos canais, que devem ser usados na comunicação. Os sistemas por satélites de comunicação apresentam como desvantagens o alto custo da transmissão dos dados e a necessidade de uma conexão (por exemplo, linha telefônica) para cada estação de referência. Um sistema global é muito complexo, pois nem o emissor, nem o receptor são sistemas portáteis. A transmissão por meio da telefonia celular atualmente é promissora principalmente devido à queda nos preços para transmissão de dados. Tem a desvantagem de que o número de usuários simultâneos é limitado pelo número de modems que há na estação de referência. A forma mais robusta para o envio das correções diferenciais é a Internet. O envio destas informações ocorre através do protocolo NTRIP (Network Transport of RTCM via Internet Protocol) que é capaz de transmitir os dados via internet, inclusive via wireless, gerenciado por um conjunto de softwares que convertem o protocolo RTCM para a linguagem de Internet em um IP. O usuário deve selecionar seu IP e configurar seu receptor móvel para RTK/GSM com uso do serviço NTRIP.

Quadro 2 - Exemplos de sistemas de comunicação para os posicionamentos em tempo real.

\begin{tabular}{|c|c|c|c|c|}
\hline Meios de transmissão & Frequência & $\begin{array}{l}\text { Alcance/capacidade de } \\
\text { transmissão }\end{array}$ & Usuário & $\begin{array}{c}\text { Tipo de } \\
\text { posicionamento } \\
\text { diferencial }\end{array}$ \\
\hline Radio Low Frequency & $<300 \mathrm{KHz}$ & Centenas de km / 300 bps & Ilimitado & DGPS \\
\hline $\begin{array}{l}\text { Radio Medium Frequency } \\
\text { (MF) }\end{array}$ & $300 \mathrm{KHz}$ a $3 \mathrm{MHz}$ & Centena de km / 100 bps & Ilimitado & DGPS (beacons) \\
\hline $\begin{array}{l}\text { Radio Very High Frequency } \\
\text { (VHF) }\end{array}$ & 30 a $300 \mathrm{MHz}$ & $2400 \mathrm{bps}$ & Ilimitado & RTK \\
\hline $\begin{array}{l}\text { Radio RDS (Radio Data } \\
\text { System) }\end{array}$ & $65 \mathrm{MHz}$ a $108 \mathrm{MHz}$ & Dezenas de km / 100 bps & Ilimitado & DGPS \\
\hline Radio $2 \mathrm{~m}$ & $144 \mathrm{MHz}$ a $148 \mathrm{MHz}$ & Dezena de km / 2400 bps & Ilimitado & DGPS, RTK \\
\hline Radio UHF & 300 a $3000 \mathrm{MHz}$ & 2400 bps & Ilimitado & RTK \\
\hline Radio $70 \mathrm{~cm}$ (Mobile UHF) & $428 \mathrm{MHz}$ & Poucos km / 9600 bps & Ilimitado & $\begin{array}{l}\text { DGPS, RTK, Network } \\
\text { RTK }\end{array}$ \\
\hline $\begin{array}{l}\text { Satélite de comunicação } \\
\text { (Inmarsat) }\end{array}$ & $1545 \mathrm{MHz}$ a $3687 \mathrm{MHz}$ & Global / >2400 bps & Ilimitado & DGPS \\
\hline Telefonia Celular & 3 a $4 \mathrm{GHz}$ & Variável / 9600 bps & $\begin{array}{l}\text { Um por } \\
\text { canal }\end{array}$ & $\begin{array}{l}\text { DGPS, RTK, Network } \\
\text { RTK }\end{array}$ \\
\hline Internet & $2,4 \mathrm{GHz}$ a $5 \mathrm{Ghz}$ & Global / > 9600 bps & Ilimitado & $\begin{array}{l}\text { DGPS, RTK, Network } \\
\text { RTK }\end{array}$ \\
\hline
\end{tabular}

Fonte: Adaptado de SEEBER (2003).

\subsection{Serviços em tempo real no Brasil}

Um dos serviços em tempo real foi implantado pela Marinha do Brasil, o ERDGPS (Estações de Referência DGPS) (BRIONES, 1999). Segundo Moreira (2011), o principal objetivo foi melhorar a acurácia da navegação marítima em portos e canais de acesso. Onze estações de referência foram instaladas junto a alguns rádios-faróis existentes na costa brasileira. As correções diferenciais eram geradas nestas estações e enviadas no formato RTCM por rádio MF, com alcance de 200 a 300 milhas, possibilitando transmissão de $100 \mathrm{bits} / \mathrm{s}$. Este serviço atualmente está desativado, mas contribuiu de forma significativa com o posicionamento de embarcações na época em que a SA estava ativada, pois apresentava acurácia melhor que 
$3 \mathrm{~m}+2$ ppm da distância de separação entre as estações.

Desde 2009 o Instituto Brasileiro de Geografia e Estatística (IBGE) disponibiliza um serviço nacional gratuito denominado RBMC-IP (Rede Brasileira de Monitoramento Contínuo dos Sistemas GNSS em tempo real) (Figura 8). Este serviço atende aos usuários que fazem uso da técnica RTK ou DGPS nos seus levantamentos, utilizando o protocolo NTRIP para disseminar as correções diferenciais (SOUZA; GARNÉS; MARQUES, 2014). No serviço, o usuário seleciona de qual estação RBMC-IP deseja receber estas informações (COSTA et al., 2009).

Figure 8 - Esquema do posicionamento em tempo real por meio do NTRIP.

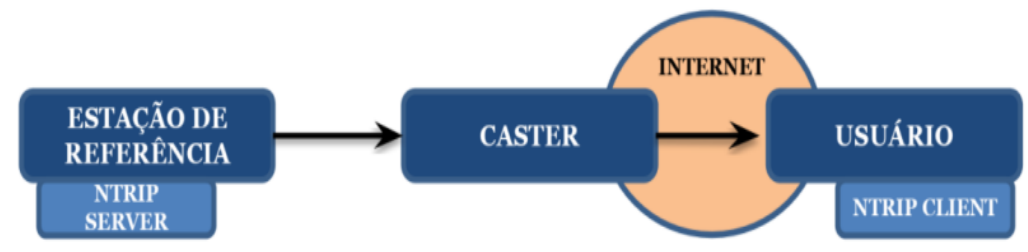

Fonte: Os autores (2020).

Ainda se pode contar com outros serviços globais comerciais disponíveis para o Brasil. Entre eles cita-se o RTG (Real Time Gipsy) e o RTX (Real-Time Extended). O primeiro também é denominado de GDGPS (Global Differential GPS) e conta com 53 estações de referência que formam a rede C-Nav GcGPS (MOREIRA, 2016). Segundo Ramos (2007), o sistema WADGPS RTG continental usa algoritmos de correção (WCT- Wide Area Correction Transform) que fornecem um único conjunto de correções para toda uma área continental. São aplicadas as correções para as órbitas e relógios dos satélites GPS ou GPS/GLONASS. Parte destas estações analisa e monitora a latência e a confiabilidade real da transferência de dados em um centro de processamento do JPL (Jet Propulsion Laboratory). As correções diferenciais são enviadas via links de comunicações terrestres aos centros de controle dos satélites geoestacionários para retransmissão aos usuários do sistema.

Em 2011 foi lançada a tecnologia RTX da Trimble, ela não requer estações de referência locais e reúne vantagens do RTK com o PPP, sendo similar ao método de PPP-RTK. Emprega correções globais de satélites estendendo a área de cobertura do RTK e proporciona precisão centimétrica em tempo real em qualquer lugar na superfície da Terra ou próximo a ela (LEANDRO et al., 2012). Essa nova técnica se baseia na geração e entrega de correções precisas de satélites (ou seja, órbita, relógios e outros) em escala global, por meio de um link de satélite ou da Internet.

\section{PESQUISAS ASSOCIADAS A APLICAÇÕES PRÁTICAS}

Com a evolução nos receptores GNSS que passaram a disponibilizar a execução do posicionamento em tempo real, a um custo mais acessível, bem como, a evolução do formato RTCM para as correções diferenciais ao longo dos anos e do meio de comunicação disponível para esta transmissão houve uma grande expansão do emprego destes sistemas de posicionamento a nível mundial em diversas aplicações. Destaca-se que, embora algumas destas aplicações possam ser efetuadas também a partir de outros métodos, o tempo real é almejado, pois apresenta algumas vantagens, por exemplo, a obtenção de coordenadas precisas, sem a necessidade de se efetuar pós-processamentos.

A seguir são abordadas algumas pesquisas que envolvem diferentes aplicações práticas com o posicionamento em tempo real, dentre as inúmeras possibilidades existentes, que foram desenvolvidas em âmbito nacional. No Brasil estas aplicações ocorrem majoritariamente a partir de uma única estação de referência, mesmo que o usuário esteja empregando o serviço da RBMC-IP. Contudo, o posicionamento de uma estação móvel a partir de correções geradas por uma rede de estações de referência está se tornando possível com o emprego dos serviços privados globais como o RTG e RTX. 


\subsection{Navegação terrestre, marítima e aérea}

A navegação abrange uma gama de aplicações que requerem diferentes níveis de precisões. No caso da navegação marítima, por exemplo, o posicionamento em alto mar pode ser atendido com o posicionamento absoluto. Contudo, este método não alcança as precisões requeridas para navegação em águas rasas, onde é exigida segurança à navegação.

Os primeiros trabalhos desenvolvidos no Brasil com o posicionamento em tempo real remontam ao ano de 1994, quando o posicionamento de trens foi efetuado por meio do DGPS empregando correções diferenciais dos códigos enviadas por meio de rádio VHF (KRUEGER, 1994). Tendo sido alcançada uma acurácia 10 vezes melhor do que o posicionamento absoluto proporcionava na época. O posicionamento de veículos em tempo real foi efetuado, por exemplo, por Saatkamp (2003). Nesta pesquisa foram empregadas correções diferenciais DGPS (código suavizado pela onda portadora) enviadas por uma emissora de radiodifusão via RDS. A acurácia obtida nesta pesquisa foi entre 0,31 e 3,88 m envolvendo diferentes classes de receptores GPS e linhas de base.

$\mathrm{Na}$ navegação marítima para levantamentos hidrográficos, Krueger (1996) empregou correções diferenciais aplicando o código suavizado pela onda portadora obtendo acurácia melhor que 5 metros para a embarcação. Dentro deste contexto de aplicação, Briones (1999), utilizou o ERDGPS. Os resultados alcançados apresentaram acurácia melhor que $10 \mathrm{~m}$. O posicionamento diferencial RTG foi utilizado por Ramos et al. (2007), e Leandro et al. (2008), que indicaram a adequabilidade do sistema RTG às especificações para o posicionamento horizontal recomendadas pela IHO (International Hidrographic Organization) para Levantamentos Hidrográficos de Ordem Especial ou Inferiores. Também no contexto do posicionamento de embarcações, Nakao (2015) empregou o RTK em levantamentos batimétricos e os resultados alcançados atenderam à resolução conjunta ANEEL/ANA de 2010 (NAKAO; KRUEGER, 2017).

Uma aplicação relevante é o uso do GNSS na navegação aérea, sendo empregado rotineiramente para navegação em rota. Diversos métodos tradicionais e de alto custo vêm sendo utilizados por muitos anos. Com o avanço da tecnologia e buscando custos menores, os sistemas GNSS se tornaram uma tendência nessa área. No entanto, uma possibilidade é o uso do GNSS no pouso e decolagens de aeronaves utilizando o conceito de GBAS (Ground Based Augmentation System). Contudo, no Brasil, nenhum destes sistemas se encontra operacional. Uma das grandes barreiras existentes é a forte interferência imposta pela camada ionosférica sobre os sinais GNSS (PEREIRA, 2018).

A agricultura de precisão envolve um conjunto de tecnologias que visa promover o aprimoramento na gestão dos sistemas de produção agrícolas (MOLIN; AMARAL; COLAÇO, 2015). Esta é uma das primeiras aplicações que empregou o posicionamento em tempo real. Um exemplo desta aplicação foi realizado por Castro e Lopes (2000), onde foi instalado um sistema RTK a bordo de uma máquina agrícola na fazenda Canguiri da Universidade Federal do Paraná. A precisão do posicionamento obtido por estes autores foi da ordem do metro. Atualmente as empresas que produzem estas máquinas disponibilizam soluções RTK empregando, por exemplo, redes de celular, torres de transmissão RTK.

Atualmente, veículos aéreos remotamente pilotados (Remotely Pilloted Aircraft - RPA) vem sendo amplamente empregados no mapeamento. Em geral o posicionamento destes veículos é efetuado em tempo real através do RTK. Uma estação de referência é implantada nas imediações da área a ser mapeada, transmitindo as correções diferenciais por um rádio transmissor. Como este sinal de telemetria pode sofrer interferências durante o voo, a consolidação do PPP - RTK no Brasil torna-se promissora nesta temática.

\subsection{Monitoramento ambiental}

O monitoramento consiste na observação sistemática de parâmetros para um propósito específico, definindo informações quantitativas e qualitativas em um intervalo de tempo considerado, visando à investigação acerca de um problema. Segundo Spellerberg (2005), o monitoramento pode ser definido como a medição de entidades que mudam ao longo do tempo e espaço. Logo o posicionamento GNSS é pertinente e atende a estes requisitos, visto que ele possibilita o posicionamento, a navegação e tempo continuamente 
(HOFMANN-WELLENHOF; LICHTENEGGER; COLLINS, 2001). Na temática do meio ambiente algumas aplicações requerem o posicionamento em tempo real. Em outras este posicionamento pode fornecer agilidade na obtenção das soluções.

O controle e acompanhamento da evolução da biodiversidade marinha como, por exemplo, nos recifes artificiais é importante no que tange aos corredores de pesca e turismo sustentável, além de contribuir com a compreensão dos processos ecológicos e hidrológicos na plataforma continental. Recifes artificiais foram lançados no litoral paranaense e o seu monitoramento passou a ser feito pelo DGPS com correções enviadas por rádios VHF e posteriormente pelo RTK (KRUEGER et al., 1999). Nesta pesquisa o posicionamento em tempo real possibilitou aos mergulhadores estarem mais próximos aos recifes, cerca de 1 a 5 metros, facilitando a revisita.

A determinação de linhas de costa pode ser efetuada por meio de diferentes métodos de posicionamento GNSS, tanto em tempo real quanto em pós-processamento. A escolha dependerá do fim a que se destina, por exemplo, quando se almeja atualizar uma carta náutica, este elemento pode ser representado com uma imprecisão de até 10 metros (MARINHA DO BRASIL, 2017), contudo quando o usuário pretende analisar o avanço ou recuo da linha de costa melhores precisões devem ser alcançadas. Dentro do escopo do posicionamento em tempo real, na pesquisa efetuada por Moreira (2016), foram empregados o RTG e RTK/NTRIP. Analisando a precisão planimétrica para soluções fase/código, o RTG apresentou melhores resultados. Contudo, ao se analisar apenas as soluções fixas da fase, o NTRIP se mostrou mais eficiente. Quanto à análise de acurácia o autor indica que o RTG $(<0,35 \mathrm{~m})$ apresentou melhor resultado que o RTK/NTRIP $(<0,50 \mathrm{~m})$

Em levantamentos hidrográficos diversos parâmetros ambientais são medidos. Nestes levantamentos o nível instantâneo da água é fundamental e pode ser determinado pelo posicionamento em tempo real. No ano de 2006 o RTK OTF (On the Fly) foi utilizado no acompanhamento de variações do nível do mar associadas a variações nas altitudes elipsoidais de uma antena GNSS instalada em uma embarcação alcançando precisões centimétricas (RAMOS; KRUEGER, 2006).

O monitoramento de áreas de risco se faz necessário, pois permite a tomada de ações que tornam possível mitigar efeitos danosos aos quais estas áreas são suscetíveis. Burity (2016) utilizou o RTK/NTRIP em uma área de risco de deslizamento de massa, na cidade do Recife - PE, visando à determinação da vulnerabilidade física. Obtiveram-se erros de poucos centímetros e o RTK/NTRIP, se mostrou um meio eficaz e que pode ser aplicado no cálculo de deslizamentos.

\subsection{Levantamentos relacionados à gestão territorial.}

Em algumas aplicações como em levantamentos cadastrais rurais e urbanos, georreferenciamento de imóveis rurais, os posicionamentos em tempo real trouxeram grandes vantagens como soluções rápidas e precisas. Em Willgalis et al. (2002), foram empregadas as redes de posicionamento em tempo real apresentadas na seção 2.1.2 (Figura 3), no cadastro das cidade de Paranaguá - PR e Olinda - PE. Os autores indicaram que os resultados foram afetados por efeitos ionosféricos. No ano 2002 uma parcela do campus Centro Politécnico da Universidade Federal do Paraná foi cadastrada por meio do RTK e a precisão alcançada foi da ordem de centímetros (SEJAS; KRUEGER, 2002).

O RTK tem sido empregado na determinação de coordenadas dos vértices de imóveis, conforme autoriza a norma de georreferenciamento do INCRA. Coelho (2013) verificou que o método permitiu que as coordenadas dos vértices fossem determinadas em curto intervalo de tempo. Porém limitações, como o efeito de multicaminho e as perdas de sinal influenciaram na acurácia.

Euriques, Krueger e da Silva (2018) empregaram receptores de baixo custo no posicionamento de pontos sem obstruções pelo método absoluto e obtiveram acurácia planimétrica na ordem de $2 \mathrm{~m}$ e acurácia tridimensional na ordem de $3,5 \mathrm{~m}$. Os autores destacam que pelos resultados obtidos torna-se viável efetuar, por exemplo, o georreferenciamento de imagens com resolução menor que $3 \mathrm{~m}$. Com esta qualidade no posicionamento o georreferenciamento dos marcos de divisa de uma propriedade rural poderia ser levantado com este método, contudo, o entorno destes marcos deve ser avaliado. 
Prado (2001) efetuou posicionamento de pontos pelos métodos DGPS e RTK em ambiente urbano, portanto, suscetíveis ao efeito de multicaminho e interferências que dificultam a recepção das correções diferenciais por parte da estação móvel. As linhas de base variaram de $0,2 \mathrm{~km}$ a $29 \mathrm{~km}$. Os erros horizontais e altimétricos no DGPS foram inferiores a $3,5 \mathrm{~m}$ e $4 \mathrm{~m}$, respectivamente. Com o emprego do RTK tais erros foram de 6 e $15 \mathrm{~cm}$, respectivamente. Freiberger Junior (2002), em um estudo similar, detectou uma área de sombra no envio das correções diferenciais a partir da estação de referência, o que comprometeu a qualidade do posicionamento, o autor indicou neste caso a necessidade de mudança na posição da estação de referência.

Souza et al. (2013) avaliou trajetórias cinemáticas urbanas em ambientes de multicaminho na cidade do Recife, empregando o PPP-RT via software BNC 2.6 do BKG (Bundesamt für Kartographie und Geodäsie), e o RTK usando dados transmitidos via NTRIP da RBMC - IP. Os resultados da precisão média e da acurácia dos levantamentos foram para o PPP-RT de $0,47 \mathrm{~m} \mathrm{e} 10,46 \mathrm{~m}$, respectivamente. Para RTK/NTRIP obteve-se uma precisão média de $1,23 \mathrm{~m}$ e acurácia de 2,85 m. Garnés et al. (2018) em levantamentos urbanos de regularização fundiária, com o uso de bastão extensor de 4 metros, utilizou o RTK na definição dos limites dos imóveis conseguindo resultados entre $3 \mathrm{~cm}$ a $8 \mathrm{~cm}$ de acurácia posicional.

\section{PERSPECTIVAS FUTURAS}

O método PPP-RT segue em evolução, em especial no que se refere à determinação dos inteiros das ambiguidades em poucos minutos permitindo ao usuário atingir precisões centimétricas. Como explicitado anteriormente essa vertente do método tem sido chamada de PPP-RTK, e apresenta-se como uma alternativa concorrente ou complementar ao NRTK. Vários serviços têm sido desenvolvidos para atender mercados de massa, devido às vantagens comerciais e operacionais do método. Nesse sentido, a solução PPP-RTK é particularmente interessante para a região brasileira, haja vista que normalmente empregam-se redes de referência mais esparsas que àquelas utilizadas no método NRTK. Vale ressaltar que ainda há vários detalhes do método que serão investigados de forma exaustiva nos próximos anos visando sua consolidação. Grande parte desses desafios está relacionada à modelagem dos efeitos atmosféricos ou ainda à validação das ambiguidades e eliminação de outliers (ROVIRA GARCIA; JUAN; GONZALES-CASADO, 2015; OLIVEIRA JR, 2017).

Seria de grande importância para o Brasil, o desenvolvimento de um SBAS para atender o território nacional, passando posteriormente a integrar o grupo de trabalho (SBAS IWG). Tais avanços acarretariam na formação de um sistema de apoio à aviação na região brasileira. Nesse sentido, esforços têm sido realizados na FCT/Unesp através do INCT - GNSS NavAer (Instituto Nacional de Ciências e Tecnologia - GNSS no Suporte à Navegação Aérea) para desenvolver e aprimorar o GBAS - (Ground Based Augmentation System) no Brasil, sistema este que desempenha papel semelhante empregando estações terrestres próximas a aeroportos que dão suporte ao sistema (PEREIRA, 2018).

Segundo Darugna et. al. (2019), a possibilidade de posicionamento RTK com sensores de baixo custo disponíveis em smartphones foi detectada, visto que, conseguiram resolução de ambiguidade instantânea na configuração de linha de base zero. Os autores ainda indicam que o posicionamento com PPPRTK ou NRTK é mais desafiador em face de que há ruído atmosférico residual adicional. Estes são desafios a serem vencidos.

De acordo com Hein (2020), a tecnologia 5G poderá representar uma nova revolução na internet através de dispositivos móveis. Os principais alvos incluem a internet das coisas (IoT) e a banda larga móvel ultrarrápida o que poderá contribuir com a transmissão de correções diferenciais, e por sua vez, com o posicionamento em tempo real. A fusão do $5 \mathrm{G}$ com GNSS poderá resultar na melhoria do posicionamento acurado, principalmente em ambientes urbanos, contudo, será necessária a compatibilidade e a interoperabilidade do $5 \mathrm{G}$ e do GNSS.

Finalmente, é importante acrescentar que o GNSS está em processo de expansão e modernização contínua. Nesse sentido, avanços substanciais têm sido alcançados com a inclusão de novos sinais e as já citadas constelações, em operação e em desenvolvimento. Vale destacar o sinal L5 que traz mais 
possibilidades para resolução das ambiguidades e modelagem dos efeitos associados à ionosfera. Isso beneficiará diretamente às aplicações de posicionamento GNSS em tempo real.

\section{Agradecimentos}

Os autores agradecem ao professor Honoris Causa Dr. Günter Seeber pelos ensinamentos transmitidos em Geodésia Espacial, ao longo destes anos, aos docentes e discentes dos programas de pósgraduação da UFPR e UFPE, bem como, pelos projetos internacionais que foram desenvolvidos em parcerias. Agradecem ainda ao Prof. Dr. Camil Gemael (in memoriam) representando também todos os mestres da UFPR pelos ensinamentos transmitidos ao longo de nossas jornadas, da mesma forma, ao Prof. Dr. João Francisco Monico Galera representando também todos os mestres da UNESP. A primeira autora agradece a Fundação Araucária, Secretaria de Estado da Ciência, Tecnologia e Ensino Superior do Paraná (SETI) pelo financiamento da Bolsa de Produtividade em Pesquisa (CP 15/2017).

\section{Contribuição dos Autores}

Conceptualização: C.P.K. P.S.O.J. J.F.E. Metodologia: C.P.K. P.S.O.J. S.J.A.G. D.B.M.A. J.F.E. Visualização: C.P.K. P.S.O.J. S.J.A.G. D.B.M.A. J.F.E Redação-minuta inicial: C.P.K. P.S.O.J. S.J.A.G. D.B.M.A. J.F.E. Redação-revisão e edição: C.P.K. P.S.O.J. S.J.A.G. D.B.M.A. J.F.E.

\section{Conflitos de Interesse}

Os autores declaram que não há nenhum conflito de interesse.

\section{Referências}

ALVES, D. B. M. Posicionamento baseado em redes GPS utilizando o conceito de estação virtual. $165 \mathrm{f}$. Tese (Doutorado em Ciências Cartográficas) - Faculdade de Ciência e Tecnologia, Universidade Estadual Paulista, Presidente Prudente, 2008.

BRIONES, A. B. Análise do posicionamento DGPS baseado nas ERDGPS implantadas no litoral brasileiro. 104 f. Dissertação (Mestrado em Ciências Geodésicas) - Setor de Ciências da Terra, Universidade Federal do Paraná, Curitiba, 1999.

BROWN, N.; KEENAN, R.; RICHTER, B.; TROYER, L. Advances in ambiguity resolution for RTK applications using the new RTCM 3.0 master- auxiliary messages. In: INTERNATIONAL TECHNICAL MEETING OF THE SATELLITE DIVISION OF THE INSTITUTE OF NAVIGATION, $18^{\text {th }}, 2005$, Long Beach. Proceedings... Long Beach, CA, 2005. p. 73-80.

BURITY, E.F. Determinação da vulnerabilidade física em áreas de risco de deslizamento a partir do posicionamento GNSS, com técnica RTK-NTRIP. 315 f. Tese (Doutorado) - Departamento de Engenharia Civil, Universidade de Brasília, Brasília, 2016.

CASTRO, P. LOPES, R. Emprego do GPS na agricultura de precisão. 80 f. Monografia (Conclusão de Curso) - Departamento de Engenharia Cartográfica e de Agrimensura, Universidade Federal do Paraná, Curitiba, 2000.

COELHO, L. A. N. Acurácia na determinação das coordenadas dos vértices de imóveis urbanos. 176 f. Tese (Doutorado em Ciências Cartográficas) - Faculdade de Ciência e Tecnologia, Universidade Estadual Paulista, Presidente Prudente, 2013.

COSTA, S. M. A.; LIMA, M. A. A.; MOURA JUNIOR, N. J. de; ABREU, M. A.; DA SILVA, A. L.; FORTES, L. P. S. RBMC em tempo real, via NTRIP, e seus benefícios nos levantamentos RTK e DGPS. In: SIMPÓSIO BRASILEIRO DE CIÊNCIAS GEODÉSICAS E TECNOLOGIAS DA GEOINFORMAÇÃO, 2, 2008, Recife. Anais... Recife. Departamento de Engenharia Cartográfica, 
2008. p. 1-8.

DARUGNA, F.; WÜBBENA, J; ITO, A.; WÜBBENA, T.; WÜBBENA, G.; SCHMITZ, M. RTK and PPPRTK using smartphones: from short baseline to long baseline applications. In: INTERNATIONAL TECHNICAL MEETING OF THE SATELLITE DIVISION OF THE INSTITUTE OF NAVIGATION, 32 $2^{\text {nd }}$, 2019, Miami. Proceedings... Miami, Florida 2019. p. 3932-3945.

DIVIS, D. A. AS: Going the way of the dinosaur. GPS World, Duluth, USA, v.11, n. 6, p. 16-19, May 2000. ISSN 1048-5104.

EURIQUES, J. F.; KRUEGER, C. K.; SILVA, J. Z. S. Avaliação do posicionamento efetuado com receptores de navegação de baixo custo. In: SIMPÓSIO BRASILEIRO DE CIÊNCIAS GEODÉSICAS E TECNOLOGIAS DA GEOINFORMAÇÃO, 7, 2018, Recife. Anais... Recife. Departamento de Engenharia Cartográfica, 2018. p. 1-10.

FLAMENT, D.; THOMPSON, G.; AHMAD, M. SBAS interoperability the latest developments. Inside GNSS: PNT re-imagined experimental SatNav probes the future, Red Bank, NJ, v. 15, n. 4, p. 24-27, July/August 2020, ISSN 2329-2970.

FOTOPOULOS, G,; CANNON, E. An overview of multi-reference station sethods for cm-level positioning. GPS Solutions, NY, v. 4, p. 1-10, January 2001. DOI:10.1007/PL00012849.

FREIBERGER JUNIOR, J. Análise da degradação do posicionamento em tempo real com o emprego do GNRT. 136 f. Dissertação (Mestrado em Ciências Geodésicas) - Setor de Ciências da Terra, Universidade Federal do Paraná, Curitiba, 2002.

GAO, G. X.; ENGE, P. How Many Satellites Are too many? IEEE Transactions on Aerospace and Electronic Systems, v. 48, n. 4, p. 2865-2874, October 2012. DOI 10.1109/TAES.2012.6324666

GARNÉS, S. J. A. ; DINIZ, F. R. ; PESSOA, R. A. C. ; GONÇALVES, M. L. A. ; COUTINHO, I. J. ; ARCOVERDE, R. B. ; FARIAS, L. P. Projeto de Regularização Fundiária do Núcleo Urbano Novo Tapajós Igarassu Pernambuco In: SIMPÓSIO BRASILEIRO DE CIÊNCIAS GEODÉSICAS E TECNOLOGIAS DA GEOINFORMAÇÃO, 7. 2018, Recife. Anais... Recife. Departamento de Engenharia Cartográfica, 2018. p. 1-10.

GENG, J.; SHI, C.; GE, M. et al. Improving the estimation of fractional-cycle biases for ambiguity resolution in precise point positioning. Journal of Geodesy, v. 86, p. 579-589, August 2012. DOI: 10.1007/s00190-011-0537-0.

GREWAL, M. S.; WEILL, L. R.; ANDREWS, A. P. Global Positioning Systems, inertial navigation, and integration. $2^{\text {a }}$ ed. Estados Unidos: A. John Wiley and Sons, 2007.

GRINTER, T.; ROBERTS, C. Precise Point Positioning: Where are we now? In: INTERNATIONAL GLOBAL NAVIGATION SATELLITE SYSTEMS SOCIETY IGNSS SYMPOSIUM, 2011, Sydney. Proceedings....Sydney,Austrália: University of New South Wales, 2011, p. 1-15.

HEGARTY, C. J. The Global Positioning System (GPS). In: TEUNISSEN, P. J. G.; MONTENBRUCK, O ( $1^{\text {a }}$ ed.). Springer Handbook of Global Navigation Satellite Systems. Trento: Springer International Publishing, 2017. p. 197-218.

HEIMBERG, F. Untersuchungen zum operationellen einsatz des differential GPS. 202 f. Tese (Doutorado) - Institut für Erdmessung, Universität Hannover, Hannover, 1994.

HEIN, G. W. Status, perspectives and trends of satellite navigation. Satellite Navigation, v. 1, n. 22, p. 1-12, August 2020.DOI 10.1186/s43020-020-00023-x

HOFMANN-WELlenhOF, B.; LICHTENEGGER, H.; COLlinS, J. GPS Theory and Practice. $5^{\text {a }}$ ed. New York: Springer, 2001.

HOFMANN-WELLENHOF, B.; LICHTENEGGER, H.; WASLE, E. GNSS - Global navigation satellite systems, GPS, GLONASS, Galileo and more. Spring-Verlage Wien, 2008. 516p.

KEE, C., PARKINSON, B., AXELRAD, P. Wide Area Differential GPS. Navigation: Journal of The 
Institute of Navigation, USA, v. 38, n. 2, p. 123-146, Summer 1991.

KRUEGER, C. P. Posicionamento cinemático de trens. 185 f. Dissertação (Mestrado em Ciências Geodésicas) - Setor de Ciências da Terra, Universidade Federal do Paraná, Curitiba, 1994.

KRUEGER, C. P. Investigações sobre aplicações de alta precisão no âmbito marinho. 288 f. Tese (Doutorado em Ciências Geodésicas) - Setor de Ciências da Terra, Universidade Federal do Paraná, Curitiba, 1996.

KRUEGER, C. P.; SEEBER, G.; SOARES, C. R.; CAMPOS, M. A.; BOEDER, V. Aplicações do DGPS preciso em tempo real no âmbito marinho. Revista Brasileira de Cartografia, Rio de Janeiro, v. 51, n. 11, p. 59-71, Maio 1999.

KRUEGER, C. P.; GEMAEL, C.; SEEBER, G.; ROMÃO, V. M. C. Relatório de pesquisa do projeto de cooperação entre Brasil e Alemanha: Desenvolvimento de redes de referência locais visando aplicações do GPS de alta precisão em tempo real. Curitiba: 2001/12 maio. 82f.

LACHAPELLE, A.; ALVES, P. Multiple Reference Station Approach: Overview and Currente Research. Journal of Global Positioning Systems. v.1, n.2, p. 133-136, December 2002. DOI: 10.5081/jgps.1.2.133.

LANGLEY, R. B.; TEUNISSEN, P. J. G.; MONTENBRUCK, O. Introduction to GNSS. In: TEUNISSEN, P. J. G.; MONTENBRUCK, O (1 $1^{\text {a }}$ ed.). Springer Handbook of Global Navigation Satellite Systems. Trento: Springer International Publishing, 2017. p. 3-23.

LAURICHESSE, D.; PRIVAT, A. An open-source PPP client implementation for the CNES PPP-WIZARD demonstratetor. In: INTERNATIONAL TECHNICAL MEETING OF THE SATELLITE DIVISION OF THE INSTITUTE OF NAVIGATION, 28 ${ }^{\text {th }}, 2015$, Tampa. Proceedings... Tampa, Florida, 2015. p. 2780-2789.

LEANDRO D.; HUINCA S. C. M.; KRUEGER C. P.; RAMOS A. M. Análise da qualidade do posicionamento de uma embarcação em um levantamento hidrográfico. Anais Hidrográficos, Rio de Janeiro, v. 60, n. 15, p.75-85, Setembro 2008.

LEANDRO R.; LANDAU, H.; NITSCHKE, M.; GLOCKER, M.; SEEGER, S.; CHEN, X.; DEKING, A.; TAHAR, M. B.; ZHANG, F.; FERGUSON, K.; STOLZ, R.; TALBOT, N.; LU, G.; ALLISON, T.; BRANDL, M.; GOMEZ, V.; CAO, W.; KIPKA, A. real-time extended GNSS positioning: a new generation of centimeter-accurate networks. GPS World, USA, July 2012.

LI, X.; ZHANG, X.; GUO, F. Predicting Atmopheric Delays for Rapid Ambiguity Resolution in Precise Point Positioning. Advances in Space Research, v. 54, n. 1, p. 840-850, September 2014. DOI. 10.1016/j.asr.2013.07.021.

LIMA, C. M. D. A. PPP com solução de ambiguidades inteiras no contexto de rede GPS. 160 f. Tese (Doutorado em Ciências Cartográficas) - Faculdade de Ciência e Tecnologia, Universidade Estadual Paulista, Presidente Prudente, 2015.

MARINHA DO BRASIL. Normas da Autoridade Marítima para Levantamentos Hidrográficos: NORMAM 25. Diretoria de Hidrografia e Navegação, $2^{a}$ Revisão, Niterói, 2017.

MARQUES, H.A. PPP em tempo real com estimativa das correções dos relógios dos satélites no contexto de rede GNSS. 245f. Tese (Doutorado em Ciências Cartográficas) - Faculdade de Ciência e Tecnologia, Universidade Estadual Paulista, Presidente Prudente, 2012.

MOLIN, J. P.; AMARAL, L. R.; COLAÇO, A. F. Agricultura de precisão. $1^{\text {a }}$ ed. São Paulo: Oficina de Textos, 2015.

MONICO, J. F. G. Posicionamento pelo GNSS: descrição, fundamentos e aplicações. $2^{\text {a }}$ ed. São Paulo São Paulo: Editora UNESP, 2008.

MOREIRA, A. L. L. Precisão do posicionamento RTK usando correções diferenciais transmitidas pelo sistema NTRIP (RBMC-IP). 93 f. Dissertação (Mestrado em Geomática) - Departamento de 
Geomática, Universidade Federal de Santa Maria - Rio Grande do Sul, 2011.

MOREIRA, L. A. Análise da acurácia a da precisão de alguns métodos de posicionamento em tempo real. 278 f. Dissertação (Mestrado em Ciências Geodésicas) - Setor de Ciências da Terra, Universidade Federal do Paraná, Curitiba, 2016.

NAKAO, L. T. H. Análise dos métodos de posicionamento e dos parâmetros definidores da qualidade do levantamento batimétrico realizado no reservatório de Capivari-Cachoeira. $278 \mathrm{f}$. Dissertação (Mestrado em Ciências Geodésicas) - Setor de Ciências da Terra, Universidade Federal do Paraná, Curitiba, 2015.

NAKAO, L. T. H.; KRUEGER,C. P. Análise dos métodos de posicionamento e dos parâmetros definidores da qualidade de um levantamento batimétrico. BULLETIN OF GEODETIC SCIENCES - ON-LINE VERSION, Curitiba, v. 23, n. 3, July/Sept. 2017. DOI. 10.1590/S198221702017000300027.

OLIVEIRA JR, P. S. Definition and Implementation of a new service for GNSS precise position. Tese (Doutorado em Geomática) - CNAM, França, 2017.

OLIVEIRA JR, P. S.; MONICO, J. F. G.;MOREL, L. Mitigation of receiver biases in ionospheric observables from PPP with ambiguity resolution. Advances in Space Research, v. 65, n. 8, p. 19411950, April 2020. DOI. . 10.1016/j.asr.2020.01.037

PEREIRA, V. A. S. Investigação da usabilidade do GBAS no Brasil. 306 f. Tese (Doutorado em Ciências Cartográficas) - Faculdade de Ciência e Tecnologia, Universidade Estadual Paulista, Presidente Prudente, 2018.

PRADO, A. Análise da acurácia e da correlação espacial nas técnicas DGPS e RTK. 142 f. Dissertação (Mestrado em Ciências Geodésicas) - Setor de Ciências da Terra, Universidade Federal do Paraná, Curitiba, 2001.

RAMOS, A. M.; KRUEGER, C. P. Observações maregráficas empregando a técnica RTK OTF em apoio a levantamentos hidrográficos para atualização de cartas náuticas. In: CONGRESSO BRASILEIRO DE CADASTRO TÉCNICO MULTIFINALITÁRIO, 2006, Florianópolis, Anais... Florianópolis: Universidade Federal de Santa Catarina, 2006. p. 1-9

RAMOS, A. M. Aplicação, investigação e análise da metodologia de reduções batimétricas através do método GPS Diferencial Preciso. 221 f. Dissertação (Mestrado em Ciências Geodésicas) - Setor de Ciências da Terra, Universidade Federal do Paraná, Curitiba, 2007.

RAMOS, A. M.; LEANDRO, D.; HUINCA, S. M.; KRUEGER, C. P. Análise da acurácia horizontal do posicionamento GPS diferencial empregado em levantamentos hidrográficos a partir de sistemas DGPS. In: SIMPÓSIO BRASILEIRO DE GEOMÁTICA, 2, 2007, Presidente Prudente. Anais... Presidente Prudente: Universidade Estadual Paulista, 2007. p.819-827.

RADIO TECHNICAL COMMISSION FOR MARITIME SERVICES (RTCM). RTCM standard 10403.1 for differencial GNSS (Global Navigation Satellite Systems) Services - Version 3.Virgínia, Estados Unidos, 2006.

RIZOS, C.; JANSSEN, V.; ROBERTS, C.; GRINTER, T. Precise point positioning: is the era of Differential GNSS positioning drawing to an end. In: FIG WORKING WEEK, 2012, Roma. Anais... Italy: Knowing to manage the territory, protect the environment, evaluate the cultural heritage Rome, 2012, p. 6-12.

ROVIRA-GARCIA, A.; JUAN, J. M.; GONZALES-CASADO, G. A worldwide ionospheric model for fast precise point positioning. IEEE Transactions on Geoscience and Remote Sensing, v. 53, n. 8, p.45964604, August 2015. DOI: 10.1109/TGRS.2015.2402598.

SAATKAMP, E. D. Desenvolvimento e experimentação de um formato para a transmissão de correções DGPS pelo RDS no Brasil. 158 f. Tese (Doutorado em Ciências Geodésicas) - Setor de Ciências da Terra, Universidade Federal do Paraná, Curitiba, 2003. 
SEEBER, G. Satellite geodesy: foundations, methods and applications. $1^{\text {a }}$ ed. Berlin: De Gruyter, 1993.

SEEBER, G. Satellite geodesy: foundations, methods and applications. $2^{\mathrm{a}}$ ed. New York: Walter de Gruyter, 2003.

SEJAS, M. I.; KRUEGER, C. P.; HECK, B.; SEITZ, K. Estações de referência virtuais no pósprocessamento de dados GPS. In: MITSHITA, E. (Ed.). Série em Ciências Geodésicas: Pesquisas em Ciências Geodésicas. Curitiba: PPGCG, 2002, v. 2, p.113-121. ISBN 85-88783-03-7.

SEJAS, M. I.; KRUEGER, C. P. Avaliação da Qualidade do Posicionamento a partir de estações de referencia virtuais (VRS) com tempo de ocupação de uma minuto. In: SIMPÓSIO BRASILEIRO DE GEOMÁTICA, 2, 2007, Presidente Prudente. Anais... Presidente Prudente: Universidade Estadual Paulista, 2007. p. 1-10.

SEJAS, M. I; KRUEGER, C. P. Modelagem de erros a partir de redes GPS utilizando o conceito de parâmetros de correção de área - Aplicações para o posicionamento por ponto. In: CONGRESSO BRASILEIRO DE CARTOGRAFIA, 23, 2007, Rio de Janeiro. Anais... Rio de Janeiro: Sociedade Brasileira de Cartografia, 2007. p. 1-8.

SPELLERBERG, I. F. Monitoring ecological change. $2^{\text {a }}$ ed. Cambridge: Cambridge University Press, 2005.

SOUZA, A. DO N.; GARNÉS, S. J. DOS A.; MARQUES, H. M. Avaliação do Posicionamento GNSS Obtido pelos Métodos Cinemático RTK/NTRIP e PPP em Tempo Real. Revista Brasileira de Cartografia, Uberlândia, v. 66, n. 5, p. 1117-1133, 4 out 2014.

TEUNISSEN, P. J. G.; MONTENBRUCK, O. Springer Handbook of Global Navigation Satellite Systems. $1^{a}$ ed. Trento :Springer International Publishing 2017.

TEUNISSEN, P. J. G.; KHODABANDEH, A. review and principles of PPP-RTK methods. Journal of Geodesy, v. 89, p. 217-240, March 2015. DOI: 10.1007/s00190-014-0771-3.

UNITED STATES COAST GUARD (USCG). GPS Fully Operational Statement of 1995, Alexandria, Estados Unidos, 1995.

WILlGALIS, S.; SEEBER, G.; KRUEGER, C. P.; ROMÃO, V. M. C. A real time reference network for Recife, Brazil, enabling precise and reliable cadastral surveys. In: FIG INTERNATIONAL CONGRESS, 22, 2002, Washington. Proceedings... Estados Unidos. 2002. p. 1-14.

WÜBBENA, G., SCHMITZ, M.; BAGGE, A. PPP-RTK: precise point positioning using state space representation in RTK networks. In: INTERNATIONAL TECHNICAL MEETING OF THE SATELLITE DIVISION OF THE INSTITUTE OF NAVIGATION, $18^{\text {th }}$, 2005, Long Beach. Proceedings... Califórnia: 2005, p. 2584-2594.

WÜBBENA, G.; BAGGE, A.; SEEBER, G.; BOEDER, V. HANKEMEIER, P. Reducing Distance dependent errors for Real-Time precise DGPS applications by establishing reference station networks. In: ION GPS, 1996, Cansas. Proceedings... Missouri, Estados Unidos: 1996, p.1 - 9.

\section{Biografia dos Autores}

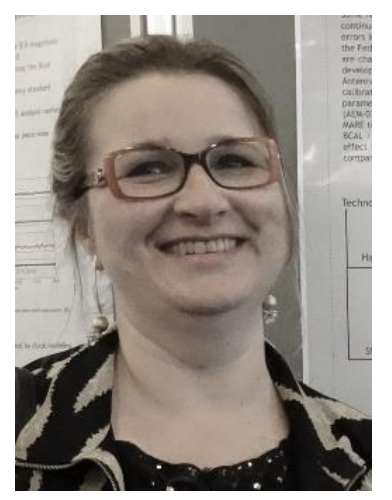

Claudia Pereira Krueger, nascida em Curitiba, Paraná, é engenheira civil pela UFPR (Universidade Federal do Paraná), Curitiba, Paraná., Brasil. Mestre em Ciências Geodésicas pela UFPR (1994); Doutora em Ciências Geodésicas, UFPR, com período de pesquisa desenvolvido junto ao Institut für Erdmesung, Universidade de Hannover (UH), Alemanha (1996) e Hidrógrafa Honorária pela Marinha do Brasil (2009). Atualmente, é docente do departamento de Geomática e dos programas de pós-graduação em Ciências Geodésicas (PPGCG) e em Engenharia de Recursos Hídricos e Ambiental (PPGERHA) da UFPR. Coordena o Laboratório de Geodésia Espacial e Hidrografia (LAGEH) e atua com pesquisas em Geodésia Espacial, Hidrografia e Posicionamento GNSS. 

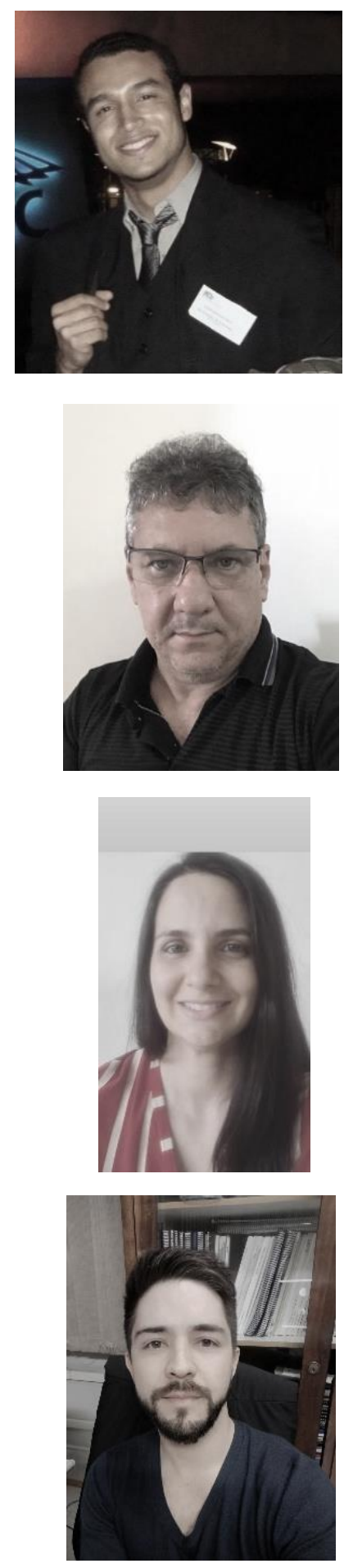

Paulo Sérgio de Oliveira Jr, originário de Nantes-SP, é engenheiro cartógrafo pela Unesp (Universidade Estadual Paulista), Presidente Prudente-SP. Durante a graduação, realizou intercâmbio na ESGT (École Supérieure des Géomètres et Topographes), Le Mans, França, e estágio no GRACE (GNSS Research and Application Centre of Excellence), Nottingham, UK. Mestre em Ciências Cartográficas (Unesp) e doutor em Geomática sob cotutela internacional (ESGT/Unesp). O doutorado foi desenvolvido em contexto industrial junto à empresa Hexagon Geosystems, provedora de serviços GNSS na Europa. Atualmente, é docente na UFPR (Universidade Federal do Paraná), Curitiba-PR, e atua com pesquisas envolvendo Geodésia e posicionamento GNSS em tempo real.

Silvio Jacks dos Anjos Garnés, nascido em Xambrê, Paraná, é engenheiro agrimensor pela UNIDERP (Universidade Anhanguera), Campo Grande, MS. Mestre (1996) e Doutor (2001) em Ciências Geodésicas pela Universidade Federal do Paraná (UFPR), Curitiba, Paraná, Brasil. Atualmente é docente do Departamento de Eng. Cartográfica da Universidade Federal de Pernambuco (UFPE), Brasil; líder de grupo de pesquisa do CNPq em Regularização Fundiária e Professor do Programa de Pós-graduação em Ciências Geodésicas e tecnologias da Geoinformação da UFPE, e atua em pesquisas envolvendo Geodésia, Astronomia, e Regularização fundiária, bem como, é desenvolvedor do programa AstGeoTop.

Daniele Barroca Marra Alves nasceu na cidade de Presidente Prudente - SP no ano de 1980. É professora Assistente Doutora do Departamento de Cartografia da Universidade Estadual Paulista - UNESP e membro do Programa de PósGraduação em Ciências Cartográficas. Possui graduação em Matemática pela FCT - UNESP (2001). Finalizou o Mestrado em Ciências Cartográficas em 2004, o Doutorado em 2008 e o Pós-Doutorado em 2011, na mesma instituição. Desde 2012 é pesquisadora do Conselho Nacional de Desenvolvimento Científico e Tecnológico $(\mathrm{CNPq})$. Suas principais áreas de atuação são a modelagem atmosférica, rádio ocultação e o posicionamento GNSS (Global Navigation Satellite System).

Jorge Felipe Euriques, natural de São Paulo-SP. Engenheiro Cartógrafo e Agrimensor pela Universidade Federal do Paraná (UFPR). Tem experiência internacional adquirida através de intercâmbio efetuado na École Supérieure des Géométres et Topographes - França. Mestre em Ciências Geodésicas pela UFPR. Desde 2014 é membro do Laboratório de Geodésia Espacial de Hidrografia do Departamento de Geomática. Tem experiência em Geociências com ênfase em Geodésia. Atualmente é aluno de doutorado no Programa de Pós-Graduação em Ciências Geodésicas - UFPR. Atua com principalmente com pesquisas relacionadas ao GNSS, Refletometria GNSS em aplicações de sensoriamento e calibração de antenas GNSS. 